\title{
É HORA DE IR PARA CASA: REFLEXÕES SOBRE O IR E VIR SEM SAIR DO LUGAR
}

IT'S TIME TO GO HOME:

THOUGHTS ABOUT GOING AND COMING WITHOUT MOVING

\author{
GABRIELA OSTROVSIKI CABRAL \\ Doutoranda em Administração - ESAG/UDESC \\ Universidade do Estado de Santa Catarina - UDESC \\ Orcid: https://orcid.org/0000-0003-1564-9753 \\ E-mail: gabrielaostrovski@hotmail.com
}

Av. Madre Benvenuta, 2007. Itacorubi. Florianópolis/SC. CEP: 88035-901

\author{
GRAZIELA DIAS ALPERSTEDT \\ Pós-doutorado na Escola de Administração da Fundação Getúlio Vargas - EAESP \\ Professora do PPG em Administração - Universidade do Estado de Santa Catarina (UDESC/ESAG) \\ Orcid: https://orcid.org/0000-0003-0144-0406 \\ E-mail: gradial@gmail.com
}

Submissão: 13/08/2020. Revisão: 05/11/2020. Aceite: 26/11/2020. Publicação: 29/12/2020. DOI: http://dx.doi.org/10.22277/rgo.v14i1.5730

\section{RESUMO}

A pandemia do novo coronavírus alterou significativamente as formas de trabalho, colocando sob holofotes o home office, adotado emergencialmente por inúmeras organizações, no intuito de manter o distanciamento social e a continuidade das atividades. Os obstáculos desta prática são distintos quando relacionados aos níveis organizacional e individual. Alguns dos desafios reconhecidos por esta modalidade de trabalho são amplamente discutidos, com a existência de publicações contendo melhores práticas. Ao refletir acerca das discussões neste campo à luz dos estudos organizacionais, observa-se uma clara ênfase na estrutura física dos locais de trabalho. Com vistas a contribuir com a temática, este artigo objetiva contribuir para uma reflexão acerca do home office no contexto da pandemia de COVID-19, sob a luz da Teoria das Organizações e na ótica do trabalhador. Para tal, foi realizada uma apreciação da literatura sobre a Teoria das Organizações, além de 34 entrevistas exploratórias realizadas com trabalhadores que iniciaram na modalidade home office devido ao isolamento social. Como resultados, identificamos que o debate sobre home office no contexto da pandemia de COVID19 sob a luz da Teoria das Organizações pode ser agrupado em cinco grupos temáticos, relacionados à: necessidade de vigília e mecanismos de controles; criação de significados por meio das estruturas físicas; ressignificações dos espaços familiares; comunicação espontânea e informal; reconstrução da rotina e criação de condicionamentos simbólicos. Para além destes, identificamos ainda reflexões subjetivas, relacionadas com a expressão do poder e identidade do grupo.

Palavras-chave: Home office. Teletrabalho. Coronavírus. Teoria Organizacional. Estrutura física. 


\begin{abstract}
The new coronavirus pandemic significantly changed the ways of working, bringing the home office into the spotlight, adopted by many organizations in an emergency, to maintain social distance and continuity of activities. The obstacles to this practice are different when related to the organizational and individual levels. Some of the challenges recognized by this type of work are widely discussed, with the existence of publications containing best practices. When reflecting on discussions in this field of organizational studies, there is a clear emphasis on the physical structure of workplaces. To contribute to the theme, this article aims to contribute to a reflection on the home office in the context of the pandemic of COVID-19, under the Organization Theory and from the worker perspective. To this end, an assessment of the literature on the Organization Theory was carried out, in addition to 34 exploratory interviews conducted with workers who started to work from home after social isolation. As a result, we identified that the debate about home office in the context of the COVID-19 pandemic in Organization Theory can be grouped into five groups, related to the need for vigilance and control mechanisms; creation of meanings through physical structures; reframing of family spaces; spontaneous and informal communication; reconstruction of routine and creation of symbolic conditioning. Also, we identified subjective reflections, related to the expression of power and group identity.
\end{abstract}

Keywords: Home office. Teleworking. Coronavirus. Organization Theory. Physical structure.

\title{
1 INTRODUÇÃO
}

Trabalhar em casa não é algo novo. O trabalho domiciliar precedeu a expansão da manufatura. Neste sistema, o trabalhador, artesão, mantinha seu ateliê em sua própria residência e era de sua responsabilidade firmar contratos com os mercadores, acordando o que deveria ser produzido, assim como os prazos de entrega. Possuía a liberdade de organizar a produção, tendo autonomia sobre a execução das tarefas e prazos (POLANYI, 2000; ZARIFIAN, 2001).

Gradativamente, a partir da Revolução Industrial, o trabalhador passou a não ser mais o proprietário dos meios de produção e, ao invés de vender o que produzia em seu ateliê, passou então a vender seus conhecimentos e habilidades, nascendo assim uma nova concepção de trabalho (POLANYI, 2000; ZARIFIAN, 2001). Ainda assim, é possível encontrar registros da realização do trabalho em casa, vinculado à produção industrial, a partir da década de 1950 (ROCHA; AMADOR, 2018).

O trabalho fora do escritório ligado às tecnologias da informação e comunicação - TICs - possui seus primeiros desenvolvimentos a partir dos anos de 1970, juntamente com os termos telecommuting ou telework. Já no final da referida década, as experiências nesta configuração se intensificaram como estratégia para diminuir o movimento entre a casa do trabalhador e seu local de trabalho (ROCHA; AMADOR, 2018). Desde então, profissionais de diferentes áreas do conhecimento vêm se inserindo nesta configuração e muitas organizações começam a adotar essa recente modalidade de trabalho.

São diversas as nomenclaturas para esta forma de trabalhar - teletrabalho, telework, trabalho remoto, telecommuting - cada uma com suas particularidades e configurações (ADERALDO; ADERALDO; LIMA, 2017; ROCHA; AMADOR, 2018). Recentemente, entretanto, uma denominação em específico foi posta sob holofotes: o home office, impulsionado em todas as partes do mundo a partir da crise causada pelo novo coronavírus. 
Identificado pela primeira vez em 31 de dezembro de 2019 na República Popular da China, o novo coronavírus (COVID-19) foi caracterizad o como uma pandemia pela Organização Mundial da Saúde (OMS) em 11 de março (MINISTÉRIO DA SAÚDE, 2020; WAN, 2020). Na época, o Brasil registrava cinquenta e dois casos confirmados e, no mundo 4.291 pessoas haviam perdido suas vidas (SANAR SAÚDE, 2020; WAN, 2020). Até o dia 13 de agosto de 2020 foram registrados mais de 20 milhões de casos de COVID-19 no mundo e, lamentavelmente, mais de 740 mil pessoas perderam suas vidas pela doença (743.487) (WHO, 2020a).

Com o objetivo de diminuir a propagação do vírus, medidas restritivas para promover o distanciamento social foram tomadas por autoridades do mundo inteiro. Entre essas medidas estão o estado de quarentena, a adoção do lockdown, o fechamento de comércios e escolas e o uso obrigatório de máscaras (WHO, 2020b). A verdade é que a pandemia do novo coronavírus alterou significativamente a vida de todos, transformando as rotinas e as relações. $E$, entre essas transformações, está a forma de como o trabalho é desenvolvido. Embora preservar a saúde seja um luxo para muitos empregados, aqueles que têm possibilidade acabaram sendo compelidos a adotar o home office de forma emergencial, como forma de manter o distanciamento social e a continuidade das atividades.

Os obstáculos desta prática são distintos. Na área de estudos organizacionais é possível dividir os impactos do home office em pelo menos dois níveis de análise que se entrelaçam: o nível organizacional e o nível individual (FELSTEAD; HENSEKE, 2017; LEITE; LEMOS; SCHNEIDER, 2019; MEROÑO-CERDÁN, 2016; PERRY; RUBINO; HUNTER, 2018). Alguns dos desafios desta prática são amplamente discutidos, com a existência de publicações que contém melhores práticas para a implementação do trabalho home office, oferecendo dicas e receitas prontas (ENDEAVOR, 2020a, 2020b; RESEARCH XP, 2020; SEBRAE, 2020).

Ao refletir acerca das discussões teóricas sobre o home office e sobre os conteúdos de tais manuais de boas práticas, à luz dos estudos organizacionais, é possível observar que o aspecto voltado à dimensão da estrutura física das organizações se destaca. Uma vez que as implicações sobre esse aspecto raramente sejam tão simples quanto sua objetividade pode fazê-la parecer (HATCH, 2013), este ensaio, teórico-reflexivo, possui como objetivo contribuir para uma reflexão acerca do home office no contexto da pandemia de COVID-19, sob a luz da estrutura física nos estudos organizacionais e na ótica do trabalhador.

O intuito é o de promover uma melhor compreensão da complexidade do tema de maneira a permitir que se amplie o entendimento de como esse aspecto, aparentemente objetivo, tem implicações profundas nos indivíduos e nas organizações. Para tanto, parte-se da apreciação da literatura na Teoria das Organizações, além do conteúdo de entrevistas exploratórias realizadas com trabalhadores que passaram a exercer suas atividades profissionais em casa, devido ao isolamento social ocasionado pela pandemia do novo coronavírus. O próximo tópico apresenta a descrição do método deste ensaio, fornecendo informações sobre as entrevistas exploratórias realizadas e seus prolongamentos.

\section{MÉTODO}

Conforme mencionado, este tópico tem como intuito descrever o método deste ensaio teórico-reflexivo, a fim de fornecer detalhes sobre as entrevistas exploratórias realizadas, indicando como foram realizadas, como se chegou aos participantes, como foram analisadas e os procedimentos éticos adotados. 
Com o estabelecimento da pandemia de COVID-19 e, passando o home office a ser uma realidade para muitas pessoas, o interesse por este campo intensificou-se. Assim, onze dias após a publicação do decreto estadual que declarou situação de emergência para todo o território do estado de Santa Catarina (DA SILVA, 2020), deu-se início à realização de entrevistas/conversas exploratórias com pessoas que passaram a trabalhar de suas casas devido ao novo coronavírus.

Assim, foram realizadas 34 entrevistas com trabalhadoras e trabalhadores que adotaram o home office exclusivamente pela pandemia de COVID-19, sendo que apenas dois dos entrevistados tiveram experiência anterior com essa modalidade. Todas as entrevistas ocorreram através da plataforma de videochamadas Google Meet $^{\circledR}$, $\operatorname{com}$ a gravação de áudio e vídeo, após autorização dos participantes por meio de Termo de Consentimento Livre e Esclarecido.

Salienta-se que as entrevistas realizadas fazem parte de um projeto de pesquisa maior, e, assim, foram feitas com o intuito de se estabelecer uma primeira aproximação com o fenômeno. Desta forma, o objetivo das entrevistas exploratórias foi investigar a relação de trabalhadoras e trabalhadores com o home office, no contexto da pandemia de COVID-19, explorando suas experiências.

Com relação ao roteiro utilizado, três blocos temáticos foram estabelecidos para guiar a conversa com os participantes: a quarentena e o início do home office; as percepções sobre o dia a dia no home office durante a pandemia, e; impressões sobre o home office. Realizouse análise interpretativa das entrevistas exploratórias com o auxílio de um processo de categorização simples, utilizando-se nomes fictícios para garantir a privacidade das entrevistadas e entrevistados.

O próximo capítulo deste ensaio, portanto, apresenta algumas categorias construídas na forma de grupos temáticos, de caráter teórico-empírico, entre a apreciação da literatura e as questões emergentes das entrevistas exploratórias realizadas nas primeiras semanas da pandemia de COVID-19. Na sequência, parte-se para o fechamento do ensaio e para as considerações finais.

\section{QUANDO HOME VIRA OFFICE}

Conforme indicado, o novo coronavírus (COVID-19) foi caracterizado como uma pandemia pela Organização Mundial da Saúde (OMS) em 11 de março de 2020 (MINISTÉRIO DA SAÚDE, 2020; WAN, 2020), pondo sob holofotes o home office, impulsionado em todas as partes do mundo com o objetivo de promover o distanciamento social e, assim, diminuir a propagação do novo coronavírus,

$\mathrm{Na}$ esteira das provocações e discussões sobre esta modalidade de trabalho estão a cultura organizacional, os vínculos institucionais, a motivação, a liderança, o prazer e o sofrimento no trabalho, a sobrecarga de trabalho, a comunicação, além das implicações na vida pessoal e profissional (FELSTEAD; HENSEKE, 2017; LEITE; LEMOS; SCHNEIDER, 2019; MEROÑO-CERDÁN, 2016; PERRY; RUBINO; HUNTER, 2018).

Grande parte das pesquisas sobre o assunto tratam da necessidade de planejamento, organização e período de adaptação, tanto para a organização quanto para o trabalhador. Outras ainda sugerem a realização de sensibilização para aqueles que dividem o mesmo ambiente do colaborador, comumente seus familiares (FELSTEAD; HENSEKE, 2017; LEITE; LEMOS; SCHNEIDER, 2019; MEROÑO-CERDÁN, 2016; PERRY; RUBINO; HUNTER, 2018). 
Entre as dicas estão levantar-se e vestir-se de maneira profissional, ter um espaço exclusivo para exercer as atividades, diferenciar o espaço do trabalho e das refeições, estruturar o local de trabalho, atentar para os móveis e a iluminação, sinalizar a hora do trabalho para quem mora na mesma casa, como o uso de crachá da empresa, entre outros aspectos (ENDEAVOR, 2020a, 2020b; RESEARCH XP, 2020; SEBRAE, 2020).

Ao refletir acerca das discussões teóricas sobre o home office e sobre os conteúdos de tais manuais de boas práticas, à luz dos estudos organizacionais, é possível observar que o aspecto voltado à dimensão da estrutura física das organizações se destaca.

Em um primeiro olhar, as estruturas físicas aparentam ser puramente objetivas devido à sua tangibilidade, como ensina a visão moderna da Teoria das Organizações. Entretanto, elas são muito mais que construções sólidas e objetos palpáveis, pois possibilitam a teorização no âmbito das organizações em diversas perspectivas, por seu caráter simbólico. Com esse destaque, Hatch (2013) relembra a pesquisa de Hawthorne liderada por Elton Mayo, professor da Universidade de Harvard, entre 1920 e 1930. Tal pesquisa indica o início do interesse dos teóricos organizacionais em estudos envolvendo a estrutura física das organizações.

A pesquisa de Hawthorne, ao buscar identificar o impacto das mudanças no ambiente físico na produtividade do trabalhador, trouxe a constatação de que o incremento desta mesma produtividade era ocasionado não pelo ambiente em si, mas pela interpretação dos trabalhadores acerca da atenção que estavam recebendo, o que os fazia especiais. Foi nesse sentido que o aumento da motivação dos trabalhadores explicava o aumento da produtividade (MAYO; 1945).

A conclusão da experiência de Hawthorne de que a produtividade havia sofrido alterações por influências sociais, e não pelas mudanças na estrutura física, levou ao desinteresse pela temática. Hatch (2013) destaca, entretanto, que equipe de Elton Mayo não identificou que o aumento da motivação, e assim da produtividade, só aconteceu, pois, houve mudança na estrutura física (HOMANS, 1950).

Cinquenta anos se passaram para que a temática voltasse a ser alvo de pesquisadores, os quais reviveram esse campo de estudo através da investigação dos elementos básicos da estrutura física - geografia organizacional, layout, paisagismo, arquitetura e decoração características mais rotineiramente estudadas (HATCH, 2013; DE PAOLI; SAUER; ROPO, 2019).

Um olhar para a temática traz à tona a ideia de materialidade nos estudos organizacionais. Como aponta Orlikowski (2007), o social e o material estão intimamente relacionados entre si. Portanto, não há nada social que também não seja material (ORLIKOWSKI, 2007). Nessa linha de pensamento, importantes pistas analíticas podem ser encontradas quando se alinha o social e o material como elementos interdependentes na vida organizacional.

Tal perspectiva de análise substitui a ideia de materialidade como aparatos préformados às relações realizadas, entendendo a existência de recursividade entre o social e o material, assim como a emergência de ambos a partir do processo de ação (ORLIKOWSKI, 2007), ou a partir das relações realizadas.

Sob essa perspectiva, Orlikowski (2009) reconhece que as práticas sociais são todas sociomateriais. A sociomaterialidade, por sua vez, molda os limites e possibilidades de organização diária. As práticas organizacionais no contexto do home office parecem cada vez mais imbuídas de sociomaterialidade, que emergem na vida cotidiana do isolamento social.

Com o intuito de explorar o assunto, organizou-se as próximas seções a partir de um olhar para a literatura e outro para a prática do home office, extraindo das entrevistas 
exploratórias com profissionais que foram conduzidos à esta prática de forma repentina, categorias que se destacaram no atual contexto da pandemia.

\subsection{NECESSIDADE DE VIGÍLIA: CRIADA OU DESVELADA?}

O comportamento dos seres humanos é moldado pelas estruturas físicas que ocupam. Essa afirmação é de Pfeffer (1982), teórico defensor da perspectiva moderna e da inclusão dos estudos sobre estrutura física na teoria organizacional. Hatch (2013) discute esse assunto, assumindo que os projetos arquitetônicos de um edifício podem de fato reforçar os valores organizacionais, causando impressões, intencionais ou não, nos funcionários e stakeholders. Akyildiz e Polat (2018) atentam para a necessidade de planejamento, que envolve diversas estratégias para afetar o comportamento social.

Tais estudos defendem que a estrutura física também tem implicações da vida da organização e do trabalhador. Neste ponto, surge a primeira constatação sobre a transição para o home office sob o olhar da estrutura física das organizações: ao sair do escritório para casa, o trabalhador altera a geografia de seu ambiente de trabalho, modifica o layout de sua sala, assim como altera significativamente os recursos arquitetônicos e a decoração do ambiente do qual estava habituado a trabalhar.

Logo, se o comportamento dos seres humanos é moldado pelas estruturas físicas que ocupam, como Pfeffer (1982) expõe, surge a reflexão: aqueles que, drasticamente e repentinamente passaram a trabalhar remotamente a partir de suas casas, sofreram algum impacto, uma vez que a estrutura física em que exerciam suas atividades profissionais mudou completamente?

As entrevistas exploratórias revelaram que tanto subordinados quanto gestores perceberam alterações em vários aspectos de suas vidas com a mudança do escritório para casa. Um exemplo disso advém dos novos mecanismos de controle que passaram a ser exercidos, como mostra o depoimento de Maria Natália ${ }^{1}$ segundo o qual, todas as manhãs, no horário previsto para o início do trabalho, sua supervisora envia uma mensagem desejando bom dia aos integrantes de sua equipe, esperando o retorno de todos.

Tal forma de agir foi interpretada pela entrevistada como um mecanismo de controle, com o objetivo de verificar a disponibilidade da equipe para o início das atividades do dia. Com a separação geográfica e sem a possibilidade de "olhar quem chegou e em qual horário", a troca de mensagens entre a equipe sinaliza que a pessoa "chegou no escritório". Como observado por Hatch (2013), além da proximidade e da distância, teóricos organizacionais modernistas interessam-se pelas dimensões abertura e visibilidade, que dizem respeito à ausência de limites físicos entre gerência e subordinados, o que permite a supervisão direta, de maneira facilitada, com a identificação por parte da chefia de estações de trabalho vazias, por exemplo.

Desta forma, as entrevistas exploratórias levantam o questionamento sobre a visão de algumas organizações, que pode estar atrelada ainda a uma perspectiva modernista (Hatch, 2013). Tal perspectiva entende que a distância física e geográfica entre a equipe e o gestor pode significar ausência de visibilidade e, portanto, de controle. No caso em específico, as mensagens diárias no início do expediente podem refletir a necessidade de o gestor 'ver' se sua equipe está disponível na estação e trabalho, ou se chegou no escritório na hora correta:

\footnotetext{
${ }^{1}$ No momento da entrevista Maria Natália atuava há 9 anos na organização, em regime CLT; divorciada, 57 anos, pós-graduação completa.
} 
"como líder, nunca sei se a pessoa não respondeu porque está trabalhando ou porque está dormindo".

O relato de Maria Fernanda² demostra uma provável transferência da interpretação do ambiente físico tradicional para o home office, corroborando o debate sobre a mudança de comportamento pela alteração da estrutura física, apontada por Pfeffer (1982). Como complemento, Maria Fernanda revela que precisa avisar sua equipe todas as vezes que necessita ausentar-se do computador por alguma necessidade fisiológica. A impossibilidade de compartilhamento do mesmo ambiente exige um substituto ao contato visual acerca de seu deslocamento, o que não ocorria antes do home office.

Tais apontamentos levam à reflexão sobre a vigília dos gestores aos seus subordinados. Será que a aparente necessidade de controle se originou com o distanciamento social ou foi apenas desvelada com a adoção do home office? Pode-se inferir que esse aspecto pode estar relacionado à falta de preparo para a mudança, havendo uma transferência do modus operandi tradicional para o home office, sem uma preparação para tal.

\subsection{FORJANDO SIGNIFICADOS}

Ainda que as estruturas físicas transmitam num primeiro momento pura objetividade, sua investigação revela que estão repletas de simbolismos e significados. O espaço e com ele seus dispositivos não são apenas um fenômeno físico, mas social, necessitando ser considerado em sua estreita relação entre arranjos espaciais e vida social (AKYILDIZ; POLAT, 2018). Tal constatação pode ser realizada a partir da imaginação de um lugar frequentado na infância, como por exemplo, uma praia, uma casa, uma sorveteria. É provável que esse lugar esteja carregado de significados que causam reações diversas.

A princípio, os indivíduos reagem a imagens de lugares familiares, por meio da criação de um sentido simbólico para tais espaços e ambientes, tornando-os significativos para si. Essa combinação, de fisicalidade com significado, transforma as estruturas físicas e suas características em símbolos. A criação de símbolos, por sua vez, nem sempre é espontânea. Nesse sentido, organizações criam ambientes sensoriais através da combinação de recursos do design - janelas, iluminação, revestimento, móveis, cores, odores, entre outros -, forjando significados. Este arranjo de recursos transmite impressões, refletindo valores e estratégias, exprimindo a identidade organizacional. O ambiente sensorial criado produz respostas fisiológicas que podem influenciar no desempenho e no comportamento humano. Este potencial para comunicar significados por meio de estruturas físicas fornece às organizações acesso ao poder simbólico; permite que transmitam o significado que desejam, por meio de um design cauteloso e cuidadoso de suas edificações e arquitetura (RESENDE; DEMO; NASCIMENTO, 2019; HATCH, 2013; CARRIERI; PAULA; DAVEL, 2008).

Esse poder simbólico é retratado na entrevista de João Vitor ${ }^{3}$, que fornece pistas sobre a criação induzida de significados. Em determinado momento de sua fala, João Vitor revela que recebeu um pedido de um dos colaboradores de sua equipe solicitando autorização para frequentar a sede da empresa, afirmando que "se sentia bem no escritório", por isso gostaria de trabalhar de lá, ainda que todo o quadro de funcionários estivesse exercendo suas

\footnotetext{
${ }^{2}$ No momento da entrevista Maria Fernanda atuava há 8 meses na organização, em regime CLT; solteira, 25 anos, superior incompleto.

${ }^{3}$ No momento da entrevista João Vitor atuava há 2 anos e meio na organização, em regime societário; solteiro, 28 anos, superior completo.
} 
atividades remotamente. João Vitor, enquanto sócio fundador da empresa, revelou ter ficado lisonjeado com o pedido. Segundo ele, no momento da fundação da empresa, ele e os demais fundadores pensaram "em cada detalhe" no que se refere à decoração e arquitetura, a fim de construir um ambiente agradável aos funcionários.

Por outro lado, a declaração do sócio fundador sobre a valorização do ambiente organizacional físico conduz a análise sobre o colaborador e uma reflexão sobre seu pedido. Até que ponto o pedido para retornar ao ambiente físico da organização se deu pela razão por ele atribuída? Em que medida a organização ofereceu os recursos necessários - tangíveis e intangíveis - para que este funcionário pudesse exercer suas atividades em casa? Nesse ponto, chama a atenção a solicitação de um funcionário que poderia trabalhar de casa, sem se expor ao vírus em circulação, de pedir permissão para deslocar-se para a empresa. O que o levou a fazer tal pedido?

Em contrapartida, surge a inquietação relacionada ao poder das organizações de comunicar significados por meio de estruturas físicas. Como João Vitor mencionou, ele e os demais fundadores pensaram em todos os detalhes. Este "pensar nos detalhes" envolve pensar em significados. Pensar em como desejam que seus colaboradores se sintam. Se isto aconteceu, ao receber o pedido do funcionário para trabalhar na empresa, João Vitor pode ter concluído que os significados que desejavam transmitir foram interpretados da forma que imaginaram.

Leonardi (2011), ao discutir a questão sociomaterial, observa como a imbricação entre o material e o social favorece ou impede determinadas possibilidades de ação. Nesse sentido, ao encontrar restrições ou possibilidades de ação, os atores humanos fazem escolhas sobre as formas de imbricamento, a fim de produzir novas rotinas. Esse processo de recursividade produz uma interação contínua na direção de novas imbricações entre o social e o material, que, por sua vez, originam novas possibilidades e obstáculos para a ação, fazendo surgir novas possibilidades de ação e assim por diante. Seria esta a razão do pedido do funcionário ao João Vitor?

\subsection{SINTA-SE EM CASA, MAS LEMBRE-SE QUE NÃO ESTÁ TOTALMENTE NELA}

A maioria de nós sente fortes emoções ao ser exposto a ambientes familiares, uma vez que a combinação de fisicalidade com significado transforma as estruturas físicas e suas características em símbolos (RESENDE; DEMO; NASCIMENTO, 2019; HATCH, 2013; CARRIERI; PAULA; DAVEL, 2008). Repentinamente, diversos trabalhadores tiveram que deixar seus escritórios e passaram a trabalhar em suas casas. A princípio se poderia pensar que o próprio lar é o lugar mais familiar que existe. Mas, como uma mudança brusca e não planejada pode interferir no desempenho das atividades profissionais e na subjetividade do trabalhador?

O fato é que a casa do trabalhador nem sempre é um lugar apropriado para a execução de atividades profissionais. Da mesma forma, nem sempre em uma casa encontram-se elementos pensados para proporcionar um ambiente atrativo que estimule o trabalho e o desempenho das atividades, ou, ainda, conforto na execução das tarefas, tais como móveis ergonômicos, iluminação apropriada dos ambientes, cores estimulantes e objetos decorativos. Assim, a implantação do home office, de maneira repentina e sem planejamento, pode ser interpretada como um evento complexo (ZARIFIAN, 2001) que exigiu a mobilização de saberes técnicos e emocionais por parte dos atores envolvidos, sejam eles os gestores, funcionários ou familiares. 
As publicações com melhores práticas para a implementação do home office reforçam a importância de um espaço exclusivo para exercer as atividades profissionais (ENDEAVOR, 2020a, 2020b; RESEARCH XP, 2020; SEBRAE, 2020). Contudo, o que percebemos com as entrevistas exploratórias é que a existência de um ambiente exclusivo para trabalhar, com os equipamentos necessários, como móveis adequados e boa iluminação, por exemplo, é uma exceção, não uma regra.

Realizadas no início da quarentena ${ }^{4}$, as entrevistas exploratórias deram pistas sobre o processo de adaptação ao novo ambiente de trabalho, no que diz respeito à organização do tempo e espaço. Nesse sentido, camas viraram estações de trabalho, a mesa de jantar passou a conciliar refeições e atividade profissional. Maria Letícia ${ }^{5}$, por exemplo, relatou que a empresa em que trabalha disponibilizou um notebook, mas as atividades são realizadas às vezes na cama, outras na mesa em que a família realiza as refeições, já que sua casa não dispõe de espaço adequado para exercer as atividades profissionais.

De maneira semelhante, João Augusto ${ }^{6}$ revela a falta de um espaço destinado para o trabalho em sua casa. No momento das refeições ele se desloca até o quarto, exercendo as atividades na penteadeira da esposa. Fora das refeições, utiliza a mesa de jantar.

Como relata Mari Fernanda, ao mencionar a disponibilização aos funcionários de computadores por parte da empresa: "precisa de um espaço para colocar, né? [...] Na minha casa eu não tenho espaço, no meu quarto não tem espaço, não tem bancada, não tem nada, então hoje eu estou trabalhando no quarto do meu irmão".

Como se pode observar, as falas dos entrevistados oferecem indicativos da ressignificação dos espaços e das estruturas. Ao passarem a trabalhar na mesa de jantar, na cama ou na penteadeira, os participantes atribuíram um novo significado para aqueles ambientes e objetos. A fala de Maria Fernanda sobre o uso do quarto de seu irmão para exercer suas atividades profissionais provoca a reflexão sobre os impactos do home office, imposto de maneira imediata e não planejada, na dinâmica familiar e nas relações sociais. Se todo espaço expressa significados, como trabalhadores estão enfrentando essa mudança? Quais os impactos das ressignificações dos ambientes para os trabalhadores?

\subsection{QUERIA TIRAR UMA DÚVIDA COM VOCÊ... DEIXA PRA LÁ!}

O compartilhamento de espaços no local de trabalho, como corredores, copa, banheiro favorece a interação não planejada, assim como o compartilhamento de equipamentos, como a máquina de café. Assim, quanto maior a distância entre as pessoas, menor a probabilidade que esse tipo de interação ocorra (HATCH, 2013; DAVIS; LEACH; CLEGG, 2019). Esses encontros casuais, entre membros de diferentes projetos, sejam eles na biblioteca, no banheiro, no refeitório ou na copiadora, influenciam positivamente no desempenho das organizações (ALLEN, 1977).

As conversas informais, que ocorrem de forma espontânea, sem planejamento prévio, como uma reunião pré-agendada, são importantes para a comunicação entre equipes e

\footnotetext{
${ }^{4}$ Dos 34 entrevistados, trinte e um residem no estado de Santa Catarina. Através do decreto no 515, de 17 de março de 2020 o Governador do Estado de Santa Catarina declarou situação de emergência em todo o território catarinense, iniciando o regime de quarentena (SANTA CATARINA, 2020).

${ }^{5}$ No momento da entrevista Maria Letícia atuava há 10 anos na organização, em regime CLT; casada, 34 anos, superior incompleto.

${ }^{6}$ No momento da entrevista João Augusto atuava há 7 anos na organização, em regime CLT; casado, 32 anos, mestrado incompleto.
} 
criação de vínculos. Ao dividirem espaços e equipamentos, os colaboradores têm a oportunidade de dialogar sobre os projetos em que estão envolvidos, sobre seu setor e atividades desempenhadas; a discussão de dificuldades em comum pode acontecer nesses encontros, gerando soluções e insights para a resolução de problemas (ALLEN; 1977; DE SOUZA; MARCZACK; PRIKLADNICKI, 2011).

Ainda que existem diversos sistemas que auxiliam na diminuição do distanciamento entre os colaboradores, como plataforma de troca de mensagens e videoconferência, De Souza, Marczack e Prikladnicki (2011, p. 132) expõem que "a distância física entre profissionais que precisam colaborar ainda é um problema".

Essa questão se fez presente nas entrevistas exploratórias. A fala de Maria Gabriela7 torna evidente a questão do distanciamento físico como um limitador para a comunicação espontânea. Ao comentar sobre a experiência com o trabalho home office, Maria Gabriela expôs: "É diferente né, assim, o [meu gestor] senta na minha frente e falava 'ah, [Maria Gabriela], queria uma opinião tua sobre um assunto e tal' e agora fica mais distanciado [...] mas acho que é natural por conta da situação, porque não tem como né?".

Outra entrevistada, Maria Alexandra ${ }^{8}$, comentou sobre o uso de plataformas de troca de mensagens para auxiliar na comunicação neste período. Contou que foram criados dois grupos para conversas entre a equipe: o primeiro, apenas com avisos oficiais em que ela emite os comunicados e sua equipe os recebe; e, o segundo, caracterizado como um grupo livre, foi criado com o propósito de tratar de todo o tipo de assunto, relacionado ao trabalho ou não. Devido ao extenso volume de conteúdo, alguns membros da equipe solicitaram a saída do grupo, pois não estavam se sentindo confortáveis em participar.

Assim, as entrevistas evidenciam que a ausência do compartilhamento de espaços e equipamentos prejudicam as conversas espontâneas. Como apresentado por Allen (1977) e De Souza, Marczack e Prikladnicki (2011), os encontros não planejados e as conversas informais geram, muitas vezes, soluções e insights para a resolução de problemas. Além disso, vínculos afetivos e relações de amizade são criadas e fortalecidas. Assim, quais os impactos do home office na comunicação da equipe, na troca de informações e no fortalecimento das relações pessoais entre os colaboradores? Em que medida as equipes sentiram prejuízo nas suas relações e no compartilhamento de informações, ao migrarem para o home office de maneira súbita?

\subsection{ROTINAS EM RECONSTRUÇÃO: CONDICIONANDO COMPORTAMENTOS}

O ambiente físico revela localização - casa, trabalho, shopping, praia - e cada um desses lugares pode estimular rituais próprios, indicando, segundo alguns autores, a influência que os espaços possuem no comportamento social a partir de símbolos. Geralmente, algumas das respostas ao espaço físico são automáticas, como fazer o sinal da cruz ao passar em frente a uma igreja para os praticantes do catolicismo, e estão carregadas de lembranças, crenças e significados. Chama-se tais reações de condicionamento simbólico pois, são símbolos que condicionaram tais comportamentos (KOPEC, 2018; HATCH, 2013).

Dos trinta e quatro entrevistados, apenas um teve uma experiência prévia com o trabalho remoto, em outra organização. Todos os demais estavam experimentando o trabalho

\footnotetext{
${ }^{7}$ No momento da entrevista Maria Gabriela atuava há 10 anos na organização, como servidora pública; casada, 34 anos, mestrado completo.

${ }^{8}$ No momento da entrevista Maria Alexandra atuava há 5 anos na organização, como servidora pública; divorciada, 32 anos, mestrado completo.
} 
remoto pela primeira vez. Com tempo de atuação na empresa variando de três meses a 16 anos, todos possuíam uma rotina relacionada à organização do trabalho. Ao saírem do escritório para a casa, inesperadamente e forçadamente, questões Ihes foram impostas: como agir? qual a nova rotina? onde trabalhar? como trabalhar? Algumas organizações mantiveram a rotina anterior ao home office, delimitando ao trabalhador limites na reconstrução dessa nova rotina.

Maria Carolina ${ }^{9}$ relata que a organização em que atua estabeleceu a manutenção do horário habitual, realizando as pausas previstas no horário costumeiro. Assim, ela segue à risca o exigido: começa pontualmente às nove horas e encerra as atividades às 18 horas, realizando nesse período dois intervalos de quinze minutos e uma hora para o almoço. Comunicou seus pais, com quem reside, para não entrarem no quarto se a porta estiver fechada, pois este é um indicativo de que está trabalhando. Nesse exemplo, a porta fechada por ser entendida como um símbolo, que condiciona tanto o comportamento de Maria Carolina como de seus pais. Desse modo, ao perceberem a porta fechada atribuem um tipo de relação diferente com a filha. Indicar aos moradores da residência que se está trabalhando por meio de símbolos, criando assim condicionamentos simbólicos, é uma prática comum, estando frequentemente nos manuais de boas práticas da área de gestão (ENDEAVOR, 2020a, 2020b; RESEARCH XP, 2020; SEBRAE, 2020). Todavia, grande parte dos entrevistados não estabeleceram limites como Maria Carolina cita, seja por falta de conhecimento ou de condições materiais. Além de reconstruírem suas rotinas em um novo ambiente, em muitos casos com seus familiares, diversos trabalhadores sentiram o agravo da pandemia e do isolamento social nesses termos. Considerando tais relatos, não se trata apenas de trabalhar remotamente, fora do local de costume, mas de reconstruir toda uma nova rotina de trabalho reconstruindo hábitos.

\subsection{OUTRAS QUESTÕES PARA REFLEXÃO}

A temática do home office suscita outras reflexões, realizadas com base no exposto e no contexto da pandemia. Com caráter mais subjetivo, essas inquietações são discutidas a seguir, envolvendo a identidade de grupos e as relações de poder.

\subsubsection{Quem somos nós?}

Nas organizações, a divisão dos espaços por áreas de atuação - comercial, recursos humanos, marketing, financeiro, entre outras funções, é frequente. Essa divisão, na maioria das vezes, acaba fomentando o surgimento de subculturas, uma vez que os membros participantes tendem naturalmente a marcar e a defender seus espaços de atuação, definindo territórios, físicos e simbólicos (FREITAS, 2007; SMIRCICH, 1983; HATCH, 2013).

As evidências físicas desta definição de território podem se revelar nas cores do ambiente, nos móveis, na disposição das bancadas de trabalho, na decoração, entre outros elementos. Esses sinais frequentemente transmitem mensagens a respeito dos ocupantes do espaço àqueles que não pertencem ao grupo, indicando como são percebidos. A decoração do escritório, por exemplo, expressa a identidade dos indivíduos integrantes, permitindo ou não o uso de artefatos pessoais nas estações de trabalho, tais como fotos e objetos pessoais, revelando características intangíveis da organização (HATCH, 2013). Estudos sobre estrutura

\footnotetext{
${ }^{9}$ No momento da entrevista Maria Carolina atuava há 3 meses na organização, em regime CLT; solteira, 27 anos, superior incompleto.
} 
física das organizações sugerem, portanto, que a marcação física dos limites da equipe está associada com uma forte identidade do grupo. A presença de barreiras físicas, como móveis e divisórias, também pode influenciar na coesão da equipe e no relacionamento interpessoal (RICHARDS; DOBYNS, 1957; WELLS, 1965; WINEMAN, 1982).

Refletindo sobre o exposto e considerando que equipes de trabalho, inesperadamente, separaram-se fisicamente, deixando de ocupar o mesmo espaço físico, surgem algumas inquietações: membros de uma mesma equipe estão sentindo que o distanciamento físico impactou no relacionamento entre eles? Há evidências de que a distância física, não planejada, trouxe prejuízos para a coesão da equipe, uma vez que estão trabalhando fora do ambiente físico que compartilhavam? A identidade do grupo e o relacionamento interpessoal foi afetado por estarem fora do espaço que projetaram e decoraram, com artefatos que transmitiam imagens da identidade do grupo a qual pertencem? Se as relações sociais entre os trabalhadores foram construídas no escritório, a mudança de ambiente pode impactar na relação social previamente construída?

\subsubsection{Ressignificações da expressão do poder}

Conforme explorado no tópico anterior, artefatos expressam significados aos olhos dos demais, indicando traços da identidade da pessoa que o possui. Dessa forma, a adoção de móveis de alto padrão em organizações, por exemplo, pode ser um indicativo de status elevado de funcionários, clientes, acionistas e fornecedores. Nesse sentido, a hierarquia, o poder e o status podem ser comunicados pelas organizações por meio de sua estrutura física, tais como layout e tamanho das salas, decoração e, inclusive, pela exclusividade, ou não, de vaga no estacionamento. Assim, a percepção dos significados das estruturas físicas exige sensibilidade para observar não somente a existência de artefatos objetivos, mas a sua ausência (MACHADO-DA-SILVA; NOGUEIRA, 2001; HATCH, 2013)

Partindo desta discussão, algumas questões de pesquisa e da prática organizacional podem emergir: afinal, como as mudanças no ambiente organizacional provocadas pelo trabalho remoto afetam a percepção dos trabalhadores acerca do poder e suas expressões? Uma vez que as estruturas e artefatos expressam significados, a invasão da vida privada (home) na vida pública (office), com a realização de videoconferências, por exemplo, reforça as relações de poder e a expressão das posições hierárquicas ou diluem e amenizam tais questões? Ao acionarem as câmeras, os colaboradores "entram na casa do outro". Tal situação pode evidenciar as desigualdades socioeconômicas através do ambiente físico de suas residências? Ou, a ausência de uma sala imponente pode estreitar os laços entre chefia e subordinado? Essas e muitas outras reflexões surgem no contexto da pandemia de COVID19, que acelerou a adoção do trabalho a distância, envolvendo mudanças significativas nas relações de trabalho, na gestão de pessoas, entre outros fatores organizacionais que não são objeto deste ensaio.

\section{CONSIDERAÇÕES FINAIS}

O objetivo deste ensaio, teórico-reflexivo, foi contribuir para uma reflexão acerca do home office no contexto da pandemia de COVID-19, sob a luz da estrutura física nos estudos organizacionais na ótica do trabalhador. Além da apreciação da literatura sobre as temáticas envolvidas, foram realizadas entrevistas exploratórias com pessoas que passaram a exercer suas atividades profissionais em casa, devido ao isolamento social ocasionado pela pandemia do novo coronavírus. 
A triangulação de dados extraídos da literatura com as entrevistas exploratórias, originou grupos temáticos relacionados aos seguintes aspectos: necessidade de vigília e mecanismos de controle; criação de significados por meio das estruturas físicas; ressignificações dos espaços familiares; comunicação espontânea e informal; reconstrução da rotina e criação de condicionamentos simbólicos. Para além destes, foram identificados, ainda, outras reflexões relacionadas à identidade do grupo e coesão da equipe, e expressões do poder.

Cada um desses grupos temáticos reflete uma agenda de estudos futuros, com possibilidades de investigação em diversas direções. Com relação ao primeiro grupo temático, sugere-se, por exemplo, estudos sobre a identificação de alterações de comportamento de subordinados e gestores na transição para o home office. Outra direção possível refere-se ao estudo dos mecanismos de controle e a necessidade de visibilidade da equipe de trabalho por parte dos gestores. A investigação da criação de significados por meio das estruturas físicas, explorando os significados atribuídos pelos fundadores e os percebidos, é uma terceira via possível de exploração. Surge ainda, a possibilidade de investigar em que medida as organizações oferecem os recursos necessários - tangíveis e intangíveis - para que as pessoas exerçam suas atividades de casa.

As reflexões apontam, ainda, para um caminho de investigação relacionado com as ressignificações dos espaços familiares. A partir do entendimento de que todo espaço expressa significados, torna-se um desafio para a Teoria das Organizações investigar como os trabalhadores estão enfrentando a transformação de significados das estruturas físicas e quais os impactos das ressignificações desses espaços.

Outro caminho de pesquisa aponta para a área da comunicação espontânea e informal, analisando os impactos do home office na comunicação da equipe, na troca de informações e no fortalecimento das relações pessoais entre os colaboradores, além da identificação de prejuízos nas relações pessoais e na comunicação. Revela-se, também, a possibilidade de investigação na reconstrução da rotina, bem como na criação de condicionamentos simbólicos, com a identificação de símbolos e comportamentos a eles atribuídos, além do impacto do comportamento simbólico na relação familiar.

Recomenda-se estudos que analisem os impactos do distanciamento físico na coesão de equipes de trabalho e na identidade do grupo. Por fim, destaca-se pesquisas que possam identificar a percepção dos trabalhadores sobre as expressões de poder e posições hierárquicas nas novas configurações do espaço físico, incluindo o significado dos artefatos para a expressão do poder e da hierarquia.

A agenda de pesquisa aqui proposta baseia-se na constatação de que o home office no contexto da pandemia de COVID-19 não trata apenas de fazer da casa o escritório. Além da reconstrução de uma nova rotina de trabalho, trabalhadores se veem diante de uma reconstrução de hábitos. Assim como a máscara passou a integrar a vestimenta, os sapatos devem ser retirados ao se entrar em casa e as roupas devem ser trocadas a cada saída do ambiente familiar, o trabalho exigiu das pessoas novas práticas diárias. Assim, um olhar para a sociomaterialidade pode auxiliar no aprofundamento do conhecimento acerca de como objetos e artefatos materiais e imateriais reconstruídos neste momento podem contribuir para compreensão do movimento pós-pandêmico das organizações. 


\section{REFEREÊNCIAS}

ADERALDO, I. L., ADERALDO, C. V. L.; LIMA, A. C. Aspectos críticos do teletrabalho em uma companhia multinacional. Cadernos EBAPE.BR, Rio de Janeiro, v. 15, n. SPE, p. 511-533, 2017. DOI: http://dx.doi.org/10.1590/1679-395160287.

AKYILDIZ, N. A.; POLAT, H. Social Interaction Organizations of Consuption Habits: Cafeterias. International Journal of Recent Research Aspects, v. 6, n. 1, p. 1-7, 2019. Disponível em: https://www.academia.edu/41538261/Social_Interaction_Organizations_Of_Consuption_Ha bits_Cafeterias. Acesso em: 05 jun. 2020.

ALLEN, T. Managing the Flow of Technology: Technology Transfer and the Dissemination of Technological Information within the R\&D Organization. Cambridge: MIT Press, 1977.

CARRIERI, A. P.; PAULA, A. P. P.; DAVEL, E. Identidade nas organizações: múltipla? fluida? autônoma? Organizações \& Sociedades, Salvador, v. 15, n. 45, p. 127-144, 2008. DOI: 10.1590/S1984-92302008000200010.

DAVIS, M. C.; LEACH, D. J.; CLEGG, C. W. Breaking Out of Open-Plan: Extending Social Interference Theory Through an Evaluation of Contemporary Offices. Environment and Behavior, v. 52, n. 9, p. 945-978, 2019. DOI: https://doi.org/10.1177/0013916519878211.

DE PAOLI, D.; SAUER, E.; ROPO, A. The spatial context of organizations: A critique of "creative workspaces." Journal of Management \& Organization, Cambridge, v. 25, n. 2, p. 331-352, 2019. DOI: https://doi.org/10.1017/jmo.2017.46.

DE SOUZA, C. R. B.; MARCZACK, S.; PRIKLADNICKI, R. Desenvolvimento Colaborativo de Software. In: PIMENTEL, M.; FUKS, H. (Org.). Sistemas Colaborativos. Rio de Janeiro: Campus - SBC, 2011. p. 122-134.

ENDEAVOR. Trabalho Remoto: boas práticas para gerir seu time durante o período de isolamento. Gestão de Pessoas. 19 jun. 2020a. Disponível em:

https://endeavor.org.br/pessoas/trabalho-remoto-boaspraticas/?gclid=EAlalQobChMIsau43e6E6wIVE4bICh3kqQXNEAAYAyAAEgL2h_D_BwE. Acesso em: 10 jul. 2020.

ENDEAVOR. Manual de Trabalho Remoto para o Setor Público. Políticas Públicas. 19 jun. 2020b. Disponível em: https://endeavor.org.br/ambiente/manual-de-trabalho-remoto-parao-setor-publico/?gclid=EAIaIQobChMIzvDnwfGE6wIVEAiRCh3KIA1dEAAYASAAEgJJAfD_BwE. Acesso em: 10 jul. 2020.

FELSTEAD, A.; HENSEKE, G. Assessing the growth of remote working and its consequences for effort, well-being and work-life balance. New Technology, Work and Employment, Manchester, v. 32, n. 1, p. 195-212, 2017. DOI: https://doi.org/10.1111/ntwe.12097.

FREITAS, M. E. Cultura organizacional: evolução e crítica. São Paulo: Thomson, 2007. 
HATCH, M. J. Organization theory: Modern, symbolic, and postmodern perspectives. Oxford: Oxford University Press, 2013.

KOPEC, D. A. Environmental psychology for design. New York: Bloomsbury Publishing Inc., 2018.

LEITE, A. L.; LEMOS, D. C.; SCHNEIDER, W. A. Teletrabalho: uma revisão integrativa da literatura internacional. Contextus - Revista Contemporânea de Economia e Gestão, Fortaleza, v. 17, n. 3, p. 186-209, 2019. DOI:

https://doi.org/10.19094/contextus.v17i3.42743.

MACHADO-DA-SILVA, C. L.; NOGUEIRA, E. E. S. Identidade organizacional: um caso de manutenção, outro de mudança. Revista de Administração Contemporânea [online], Maringá, Edição Especial, v. 5, p. 35-58, 2001. DOI: https://doi.org/10.1590/S141565552001000500003.

MAYO, E. The Social Problems of an Industrial Civilization. Boston: Harvard University, 1945.

MEROÑO-CERDÁN, A. L. Perceived benefits of and barriers to the adoption of teleworking: peculiarities of Spanish family firms. Behaviour \& Information Technology, Eindhoven, v. 36, n. 1, pp. 63-74, 2016. DOI: https://doi.org/10.1080/0144929X.2016.1192684.

MINISTÉRIO DA SAÚDE. Resposta nacional e internacional de enfrentamento ao novo coronavírus. Brasília, 18 mar. 2020. Disponível em:

http://portal.mec.gov.br/component/content/article?id=86441. Acesso em: 10 jul. 2020.

ORLIKOWSKI, W. J. Sociomaterial practices: Exploring technology at work. Organization Studies, v. 28, n.9, p.1435-1448, 2007. DOI: https://doi.org/10.1177/0170840607081138.

ORLIKOWSKI, W. J. The sociomateriality of organisational life: considering technology in management research. Cambridge Journal of Economics, Cambridge, v.34, n. 1, p.125-141, 2009. DOI: https://doi.org/10.1093/cje/bep058.

PFEFFER, J. Developing organization theory, organizations as physical structures. In: PFEFFER, J. (ed.). Organizations and Organization Theory. Boston: Pitman, 1982.

PERRY, S. J.; RUBINO, C.; HUNTER, E. M. Stress in remote work: two studies testing the Demand-Control-Person model. European Journal of Work and Organizational Psychology, v. 27, n. 5, p. 577-593, 2018. DOI: https://doi.org/10.1080/1359432X.2018.1487402.

POLANYI, K. A grande transformação: as origens de nossa época. 2. ed. Rio de Janeiro: Compus, 2000. 
RESENDE, R. G.; DEMO, G.; NASCIMENTO, T. G. Identidade Organizacional: Em que medida a produção acadêmica nacional identifica-se com as aspirações da área? Gestão e Sociedade, v. 13, n. 36, p. 3038-3061, 2019. DOI: https://doi.org/10.21171/ges.v13i36.2507.

RESEARCH XP. Home office: manual de boas práticas. XP Investimentos. 17 mar. 2020. Disponível em: https://conteudos.xpi.com.br/wp-content/uploads/2020/03/Home_OfficeBoas-pr\%C3\%A1ticas.pdf. Acesso em: 10 jul. 2020.

RICHARDS, C.; DOBYNS, H. Topography and Culture: The Case of the Changing Cage. Human Organization, v. 16, n. 1, p. 16-20, 1957. DOI:

https://doi.org/10.17730/humo.16.1.n4gk73786v612623.

ROCHA, CHÁRIS T. M. DA; AMADOR, FERNANDA S. O teletrabalho: conceituação e questões para análise. Cadernos EBAPE.BR, Rio de Janeiro, v. 16, n. 1, pp. 152-162, jan./mar., 2018. DOI: http://dx.doi.org/10.1590/1679-395154516.

SANAR SAÚDE. Linha do tempo do Coronavírus no Brasil. Sanar Med. 2020. Disponível em: https://www.sanarmed.com/linha-do-tempo-do-coronavirus-no-brasil. Acesso em: 10 jul. 2020.

SANTA CATARINA. Decreto no 515, de 17 de março de 2020. Declara situação de emergência em todo o território catarinense [...]. Disponível em:

https://www.sc.gov.br/images/Secom_Noticias/Documentos/VERS\%C3\%830_ASSINADA.pdf . Acesso em: 10 jul. 2020.

SEBRAE. Guia do home office: produtividade no trabalho remoto. SEBRAE. 11 mar. 2020, Disponível em: https://m.sebrae.com.br/sites/PortalSebrae/artigos/guia-do-home-officeprodutividade-no-trabalho-remoto,cdbde55858311710VgnVCM1000004c00210aRCRD. Acesso em: 10 jul. 2020.

SMIRCICH, Linda. Concepts of culture and organizational analysis. Administrative science quarterly, v. 28, n. 3, p. 339-358, 1983. DOI: https://doi.org/10.2307/2392246.

WAN, W. WHO declares a pandemic of coronavirus disease COVID-19. The Washington Post. 11 mar.2020. Disponível em: https://www.washingtonpost.com/health/2020/03/11/whodeclares-pandemic-coronavirus-disease-COVID-19/ Acesso em: 05 ago. 2020.

WELLS, B. The psycho-social influence of building environments: sociometric findings in large and small office spaces. Building Science, v. 1, n. 2, p. 153-165, 1965. DOI:

https://doi.org/10.1016/0007-3628(65)90016-2.

WINEMAN, JEAN. D. Office design and evaluation: an overview. Environment and Behavior, v. 14, n. 3, pp. 271-98, 1982. DOI: https://doi.org/10.1177/0013916582143002.

WHO. WHO Coronavirus Disease (COVID-19) Dashboard. 06 ago. 2020. 2020a. Disponível em: https://covid19.who.int/. Acesso em: 05 ago. 2020. 
É hora de ir para casa:

reflexões sobre o ir e vir sem sair do lugar

WHO. WHO Coronavirus Disease (COVID-19) Dashboard. 30 jul.2020. 2020b. Disponível em: https://www.who.int/news-room/detail/29-06-2020-covidtimeline. Acesso em: 05 ago. 2020.

ZARIFIAN, P. Objetivo competência: por uma nova lógica. São Paulo: Atlas, 2001. 